\title{
AGS SLOW EXTRACTED BEAM IMPROVEMENT ${ }^{*}$
}

\author{
I. Marneris, G. Danowski, J. Sandberg, A. Soukas \\ Brookhaven National Laboratory, Upton, New York 11973 USA
}

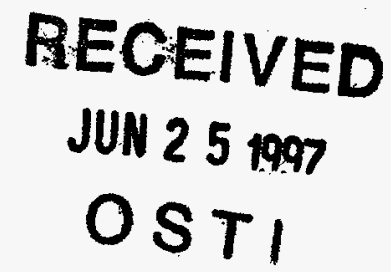

\section{Abstract}

The Brookhaven AGS is a strong focusing accelerator which is used to accelerate protons and various heavy ion species to an equivalent proton energy of $29 \mathrm{Gev}$. Since the late 1960 's it has been serving high energy physics (HEP - proton beam) users of both slow and fast extracted beams. The AGS fixed target program presently uses primary proton and heavy ion beams (HIP) in slowly extracted fashion over spill lengths of 1.5 to 4.0 seconds. Extraction is accomplished by flattoping the main and extraction magnets and exciting a third integer resonance in the AGS. Over the long spill times, control of the subharmonic amplitude components up to a frequency of 1 kilohertz is very crucial. One of the most critical contributions to spill modulation is due to the AGS MMPS. An active filter was developed to reduce these frequencies and it's operation is described in a previous paper [1]. However there are still frequency components in the $60-720 \mathrm{~Hz}$ sub-harmonic ripple range, modulating the spill structure due to extraction power supplies and any remaining structures on the AGS MMPS. A recent scheme is being developed to use the existing tune-trim control horizontal quadrupole magnets and power supply to further reduce these troublesome noise sources. Feedback from an external beam sensor and overcoming the limitations of the quadrupole system by lead/lag compensation techniques will be described.

\section{THEORY OF OPERATION}

Slow extraction from the AGS is accomplished on the 26/3 third order resonance. A set of four sextuples arranged in a,,,+-+- configuration excites the resonance just after the AGS Main Magnets are flattoped at the desired energy. The beam horizontal and vertical tunes, average radius, chromaticity and skew parameters are set to nominal values. The beam momentum spread is adjusted by $R F$ phase-back and at RF turn-off the beam is effectively debunched. The debunched beam is brought to extraction radius by slightly sloping the flattop of the MMPS. The extracted beam orbit is set by local orbit deformations and by three (3) stages of septa comprised of electrostatic, thin copper magnetic, and thick copper magnetic ejection. Extraction is accomplished in the horizontal plane. Once the extracted beam is established, a (secondary emission chamber C1OSEC) intensity signal is used for measurement and for analog feedback to a slow spill servo loop that dynamically adjusts the MMPS flattop. Since the AGS MM time constant is 3.0 seconds, it has a corresponding load breakpoint frequency of 0.05 $\mathrm{Hz}$ and thus can do a good job of average spill rate and length control and very little for higher frequency components.

\section{CORRECTION SYSTEM DESIGN AND RESULTS}

The AGS includes a set of 12 horizontal, tunetrim quadrupoles $(\mathrm{QH})$, one per superperiod, that program the fractional tune of the machine during injection, acceleration and extraction. An equivalent set of 12 is used for the vertical plane. The magnets are laminated and have a small number of turns/pole to reduce their inductance. They are installed outside the vacuum with a 6 inch, 0.063 inch wall, stainless steel round vacuum pipe. The 12 magnets are connected in series to a single, bipolar power supply (PS). The string inductance is 18 millihenry, and the resistance is 0.2 ohms. The PS is a wide-band, switchmode type with a basic switching frequency of $44 \mathrm{kHertz}$. It includes a DCCT-sensed current feedback loop and a passive LC output filter. For our application, a wide band voltage loop within the current loop was implemented with the idea of feeding back the beam harmonics 180 degrees out of phase, to try to cancel them out. The beam harmonics were measured from the external beam sensor C1OSEC. It was also essential to normalize the beam harmonic components to the averaged beam intensity because the amplitude of the harmonics changes with beam intensity variations. A lead/lag compensation was implemented to ensure stability and a bandwidth of 2 kilohertz of the system open loop transfer function. The normalized beam harmonics were then fed back to the lead/lag compensated voltage loop of the QH PS. It should be stated that the QH PS is 600 to 700 feet away from the beam harmonics signal of the C1OSEC external beam sensor. As a result it was essential to split the electronics

- Worked performed under the auspices of the U.S.D.O.E.

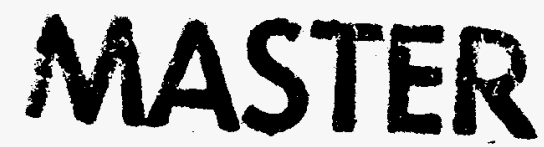


of the lead/lag network in the two different locations. For the purpose of this paper we will refer to location $A$ as the location of the beam harmonics signal, and location B as the location of the QH PS. Fig 1. is the signal flow graph of the overall system.

$G 1(s)=\frac{G 7(s)}{1+G 7(s) \cdot H 7(s)}$ is the measured voltage closed loop transfer function of the horizontal quadrupole power supply.

G2(s) is the transfer function of the lead/lag compensation network at location B.

G5(s) is the measured transfer function of the normalized beam harmonics at location $\mathrm{A}$, versus the actual voltage output of the QH magnet PS monitored at location $A$.

G6(s) is the transfer function of the lead network at location $A$.

$G 3(s)=G 1(s) \cdot G 2(s) \cdot G 5(s) \cdot G 6(s)$ is the system open loop transfer function.

$G 4(s)=\frac{G 3(s)}{1+G 3(s)}$ is the system closed loop transfer function.

V1(s) is the zero reference to our overall system to minimize the harmonics, fed at location A.

V2(s) is the normalized beam harmonics at location $A$.

\section{FIG 1.}

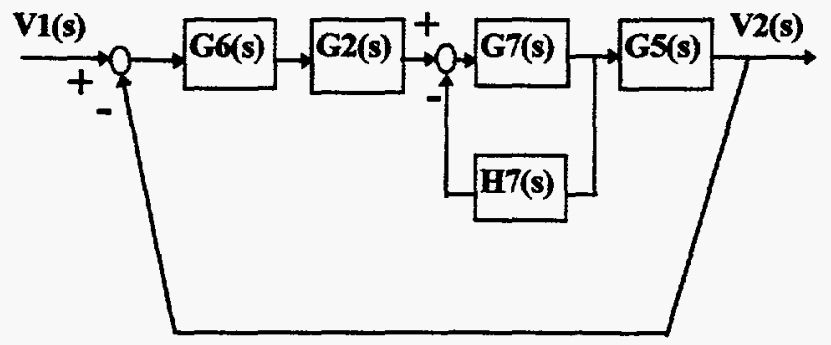

Y1(f), is the gain in (db) and P1(f) is the phase in (degrees), of the measured voltage closed loop transfer function G1(s), of the QH PS. See FIG. 2 and FIG. 3.

Y5(f), is the gain in (dB) and P5(f) is the phase in (degrees) of the measured transfer function of the normalized beam harmonics $\mathbf{G 5}$ (s) at location $A$, versus the actual voltage output of the QH PS monitored at location A. See FIG. 2 and FIG. 3.

$Y 7(f)$, is the gain in (dB) and P7(f) is the phase in (degrees), of the open loop transfer function $\mathrm{G1}(\mathrm{s}){ }^{\star} \mathrm{G5}(\mathrm{s})$ without a phase lead/lag. See FIG. 4 and FIG. 5.

Y8(f), is the gain in (dB) and P8(f) is the phase in (degrees), of the overall lead/lag compensation transfer function G2(s)*G6(s), at both locations A, B. See FIG. 4 and FIG. 5.

Y3(f), is the gain in (dB) and P3(f) is the phase in (degrees), of the system open loop transfer function G3(s) including the lead/lag compensation network. See FIG. 4 and FIG. 5.
Y4(f), is the gain in (dB) and P4(f) is the phase in (degrees), of the system closed loop transfer function G4(s). See FTG. 6 and FIG. 7.

The results of this control system are shown in FIG. 8. $\mathbf{M r}, 2$ is the normalized beam harmonics (C1OSEC) in percent at location $A$, without the implementation of this new control system. Mr,1 is the normalized beam harmonics (C10SEC) in percent at location $A$, with the implementation of this new control system. Note that we were able to correct the harmonics by a factor of 2 to 4 from $60 \mathrm{~Hz}$ to $720 \mathrm{~Hz}$. The data shown in FIG. 8 were taken on 1-27-97 during our heavy ion run. The lead/lag compensation used at the time was not exactly the one shown in FIG. 4. The new one was improved to eliminate oscillations at $1080 \mathrm{~Hz}$ and to increase the improvement of the C10SEC harmonics over the band of $120 \mathrm{~Hz}$ to $720 \mathrm{~Hz}$.
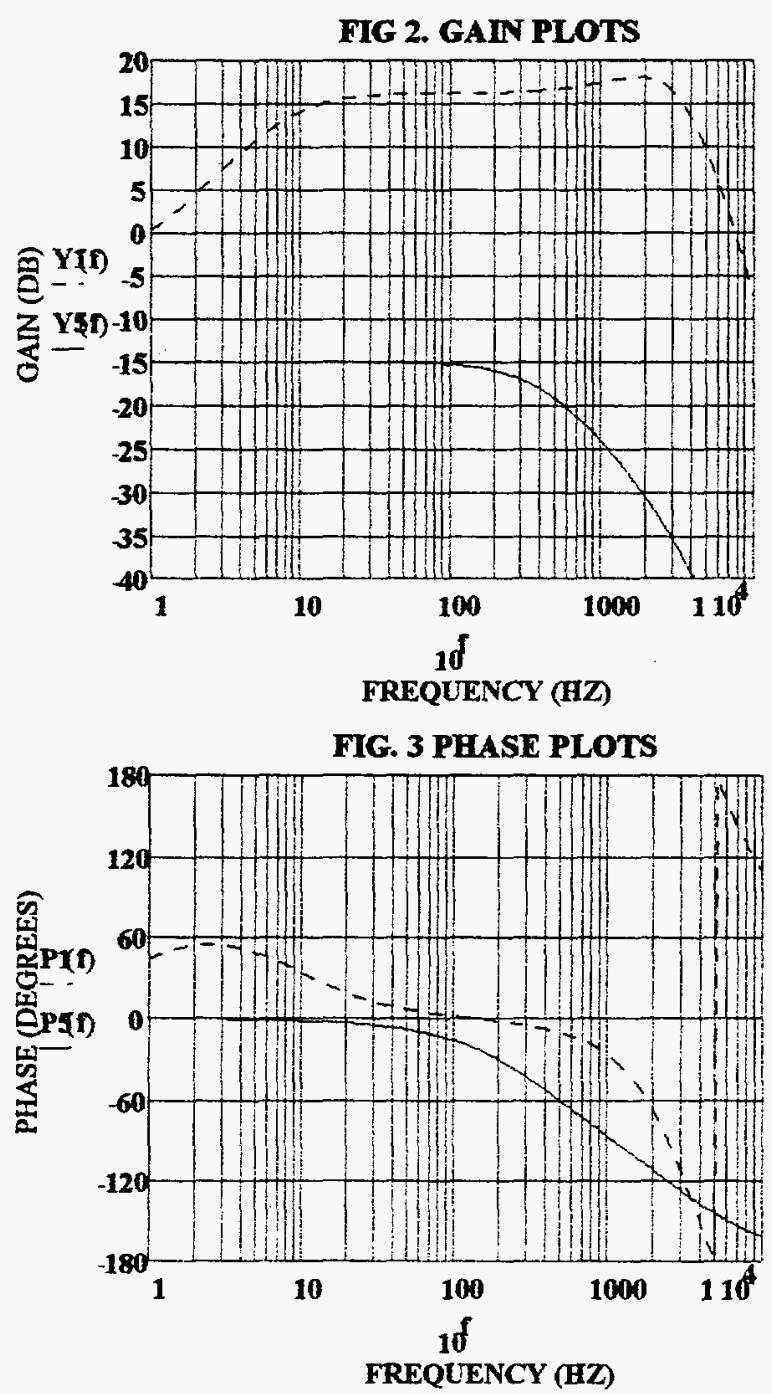

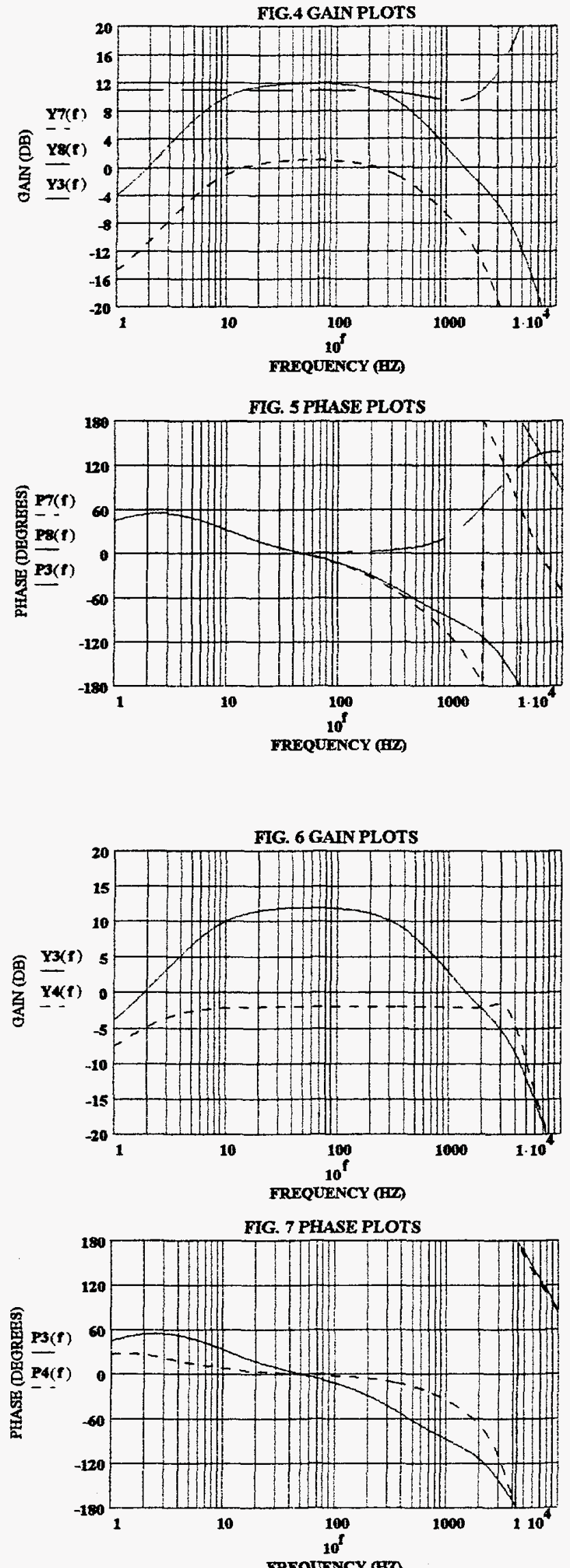

FIG. 8 RESULTS

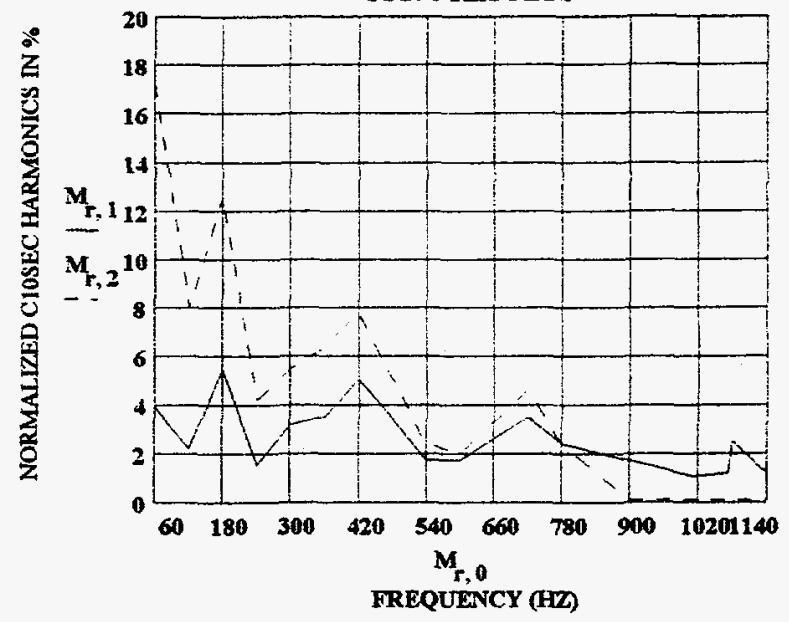

3 FUTURE PLANS

The results on FIG. 8 show a small oscillation at 1080 Hz. This is because the phase of the open loop transfer function G3(s) is more than 180 degrees, at this frequency. Design modifications were made to the

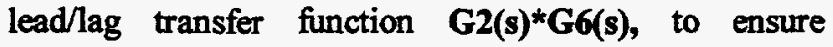
stability and maintain the open loop gain. This is one of the reasons we decided to split the lead/lag compensation in the two different locations, $A$ and $B$, mentioned above. As a result we will retest our correction system one more time with the proton slow extracted beam, to ensure we can get a factor of 4 correction on the harmonics from $60 \mathrm{~Hz}$ to $720 \mathrm{~Hz}$ without any oscillations at the zero dB point of the open loop gain Y3(f).

\section{ACKNOWLEDGMENTS}

The authors wish to thank W. Eng for his engineering support of the power supply. We also thank R. Bonati, M. Bannon, S. Savatteri and J. Funaro for their technical support in this project.

\section{REFERENCES}

[1] The active filter voltage ripple correction system of the brookhaven ags main magnet power supply. (WAR11) 1995 Particle Accelerator Conference. 


\section{DISCLAIMER}

This report was prepared as an account of work sponsored by an agency of the United States Government. Neither the United States Gnvernment nor any agency thereof, nor any of their employees, makes any warranty, express or implied, or assumes any legal liability or responsibility for the accuracy, completeness, or usefulness of any information, apparatus, product, or process disclosed, or represents that its use would not infringe privately owned rights. Reference herein to any specific commercial product, process, or service by trade name, trademark, manufacturer, or otherwise does not necessarily constitute or imply its endorsement, recommendation, or favoring by the United States Government or any agency thereof. The views and opinions of authors expressed herein do not necessarily state or reflect those of the United States Government or any agency thereof. 


\section{DISCLAMMER}

Portions of this document may be illegible in electronic image products. Images are produced from the best available original document. 